\title{
Meta-analysis on the treatment of diabetic foot ulcers with autologous stem cells
}

\author{
Jianming Guo ${ }^{1,2}$, Alan Dardik ${ }^{3}$, Kacey Fang ${ }^{4}$, Ruixue Huang ${ }^{5^{*}}$ and Yongquan Gu ${ }^{1,2^{*}}$
}

\begin{abstract}
Over the last decade, many studies have indicated a therapeutic potential for treating diabetic lower extremity ulcers with autologous stem cells. The aim of the current study was to conduct a systematic review and meta-analysis of the treatment of diabetic foot ulcers (DFUs) with autologous stem cells. The search strategy included the Pubmed, EMBASE, Web of Science, and Cochrane's Library databases. The endpoint measured was the healing of DFUs. Six eligible randomized controlled trial (RCT) studies were screened from related published studies and reviewed for meta-analysis. The overall meta-analysis showed that stem cell administration was significantly favorable for healing diabetic ulcers (mean difference (MD) $0.52,95 \%$ confidence interval (Cl) $0.38-0.65 ; p<0.00001$ ). Subgroup analyses indicated that stem cells seemed to exert similar beneficial effects on patients with ulcer size $\geq 5 \mathrm{~cm}^{2}$ (MD $0.76,95 \% \mathrm{Cl}$ $0.55-0.97 ; p<0.00001)$ and $<5 \mathrm{~cm}^{2}$ (MD 0.43, 95\% Cl 0.31-0.54; $p<0.00001$ ). Furthermore, stem cells had similar effects on patients aged $\geq 70$ years (MD $0.61,95 \% \mathrm{Cl} 0.14-1.08 ; p=0.01$ ) and $<70$ years (MD $0.47,95 \% \mathrm{Cl} 0.35-0.58 ; p<0.00001$ ). This systematic review and meta-analysis suggests a promising role for stem cells in DFU treatment. This review will pave the way to further study on the long-term effects of stem cell-based therapy and large-scale RCTs.
\end{abstract}

Keywords: Diabetic foot, Meta-analysis, Randomized controlled trial, Stem cell, Ulcer

\section{Background}

A diabetic foot is a foot with any pathology that results directly from diabetes mellitus (DM) or any of its chronic complications [1]. A diabetic foot is caused by neuropathy and/or peripheral arterial disease, especially with below-the-knee medium-to-small artery occlusions [2]. Diabetic foot ulcers (DFUs) occur in $7.2-15 \%$ of the diabetic population [3-5]. Between 5-24\% of DFUs in patients will eventually lead to limb amputation within a period of 6-18 months after the first evaluation, and about $50 \%$ of amputees die within 5 years $[1,6,7]$. Considering the environment of multidisciplinary management, novel treatment strategies are needed to mitigate and overcome these disastrous diabetic complications.

The current standard DFU treatment protocol includes wound debridement, infection management, revascularization procedures when indicated, and ulcer off-loading [8]. However, given the wound healing

\footnotetext{
*Correspondence: huangruixue@csu.edu.cn; gu15901598209@gmail.com ${ }^{5}$ Occupational and Environmental Health, Xiangya School of Public Health, Central South University, Hunan, China

${ }^{1}$ Department of Vascular Surgery, Xuanwu Hospital, Capital Medical

University, Beijing, China

Full list of author information is available at the end of the article
}

pathological characteristics of multifactorial synergistic effects, most approaches have focused on one factor, such as inflammation or growth, which limits the therapeutic efficacy [9]. In addition, due to poor outflow, some DFU patients have no option for percutaneous or surgical revascularization. For these limitations, stem cell therapy has shown promise. Clinical and basic science studies show that cell therapies can provide a comprehensive solution by addressing multiple factors during diabetic wound healing, particularly for limb ischemic patients with no other options [10].

Some small-scale clinical trials have investigated the efficacy of applying stem cells to accelerate wound healing $[11,12]$. However, the interpretation of the results may be biased by the limited statistical power and scale of the studies. On the other hand, although advanced age and ulcer size were found to have a negative effect on the healing of all diabetic foot ulcers in recent years [13-15], the effect of the age factor and ulcer size on efficacy of stem cells for treatment of diabetic ulcers is not clear. Therefore, we conducted a systematic review and meta-analysis of the published randomized 
controlled trials (RCTs) to evaluate the role of autologous stem cell administration in the treatment of DFUs.

\section{Methods}

Literature search

Two reviewers (JG and RH) independently searched the Pubmed, EMBASE, Web of Science, and Cochrane Library (Cochrane Center Register of Controlled Trials) databases, using the terms "stem cell(s)", "progenitor cells", "lipoaspirate cells" or "mononuclear cells" paired with "diabetic", and "diabetes" paired with "wound", "ulcer", "foot" or "isch(a)emia". The search was limited to clinical trial studies published in English. The final search was performed on 7 January 2017. Related original and review articles were identified manually, and references from these publications were also reviewed.

This systematic review and meta-analysis followed the Preferred Reporting Items for Systematic Reviews and Meta-analyses (PRISMA) criteria [16].

\section{Inclusion and exclusion criteria}

Studies were included if: (1) they were reported as an RCT study; (2) they recruited patients with DFUs who were assigned to either a stem cell group that accepted autologous stem cell (derived from bone marrow, peripheral blood, umbilical cord blood, or adipose tissue) transplantation treatment, or a control group that accepted only placebo or other medical treatment; and (3) they reported outcomes regarding the healing of ulcers and where the relevant data could be estimated. Furthermore, cell therapy-related adverse events were also extracted. When the same groups of patients were reported in multiple papers, only the most recent and complete paper was selected to avoid overlap.

Studies were excluded if: (1) there was no control group in the study; (2) studies lacked measurement data; (3) the same test was repeated in published literature or subgroup analyses; and (4) they were non-English articles.

\section{Data extraction}

According to the inclusion and exclusion criteria, all five authors (JG, RH, KF, AD, and YG) were involved in the literature search and data extraction. Quality was assessed according to the predefined inclusion criteria. Data regarding the first author, country of the study, publication date, characteristics of the included patients, number of participants, details of the stem cell therapy, follow-up duration, evaluation parameter such as healing rate, and incidences of adverse events were extracted.

\section{Statistical analysis}

The analysis was performed with RevMan 5.3 software (the Cochrane Collaboration, 2014, Nordic Cochrane
Center, Copenhagen, Denmark). Data were summarized as frequencies and continuous variables as standardized mean difference (SMD). The 95\% confidence intervals (CIs) were analyzed as summary statistics. $I^{2}$ was used to evaluate interstudy heterogeneity. Both the fixed effects model and the random effects model were considered in the analysis depending on the $I^{2}$ result. If the study was not statistically homogeneous, we used a fixed effects model analysis; if there was heterogeneity between studies, we used a random effects model analysis. Funnel plots were used to test for publication bias. A two-tailed $p$ value $<0.05$ was considered statistically significant. From a clinical viewpoint, subgroup analyses were performed with the following factors: age $(\geq 70$ years or $<70$ years $)$ and ulcer size $\left(\geq 5 \mathrm{~cm}^{2}\right.$ or $\left.<5 \mathrm{~cm}^{2}\right)$.

\section{Results}

\section{Search results and study characteristics}

An adapted PRISMA flow diagram [17] shows the literature screening process used in this report (Fig. 1). After careful review of the publications, six RCT studies were eligible and retrieved, including studies of bone marrowderived mesenchymal stem cells (BMMSCs; $n=1$ ), bone marrow-derived mononuclear cells (BMMNCs; $n=2)$, peripheral blood-derived mononuclear cells (PBMNCs; $n=1)$, bone marrow-enriched tissue repair cells (BMTRCs; enriched in CD90 $0^{+}$cells; $n=1$ ), and humanprocessed lipoaspirate (PLA) cells $(n=1)$ [18-21]. Among the six studies, three were from China, two were from Germany, and one was from Korea. The characteristics of the studies are shown in Table 1.

\section{Quality assessment}

The risk of biases of the included studies is shown in Fig. 2a and b. These data show that the highest risk of bias was in relation to performance and detection. Six RCT studies were included and the risk of bias for each RCT included was low.

\section{Effects of autologous stem cell therapy on the healing of lower extremity ulcers}

As shown in Fig. 3a, the meta-analysis comparing the stem cell group to the control group showed a mean difference (MD) of 0.52 (95\% CI $0.38-0.65 ; p<0.00001$ ), suggesting that stem cell-based therapy was associated with improved healing rate.

Figure $3 \mathrm{~b}$ shows the results of the subgroup analysis based on ulcer size and age. The ulcer size was $\geq 5 \mathrm{~cm}^{2}$ in two of the studies (MD 0.76, 95\% CI $0.55-0.97 ; p<0.00001)$ and $<5 \mathrm{~cm}^{2}$ in four of the studies (MD 0.43, 95\% CI 0.31-0.54; $p<0.00001$ ). Two studies included patients $\geq 70$ years (MD $0.61,95 \% \mathrm{CI}$ $0.14-1.08 ; p=0.01$ ) and four studies included patients $<70$ years (MD 0.47, 95\% CI 0.35-0.58; $p<0.00001$ ). 


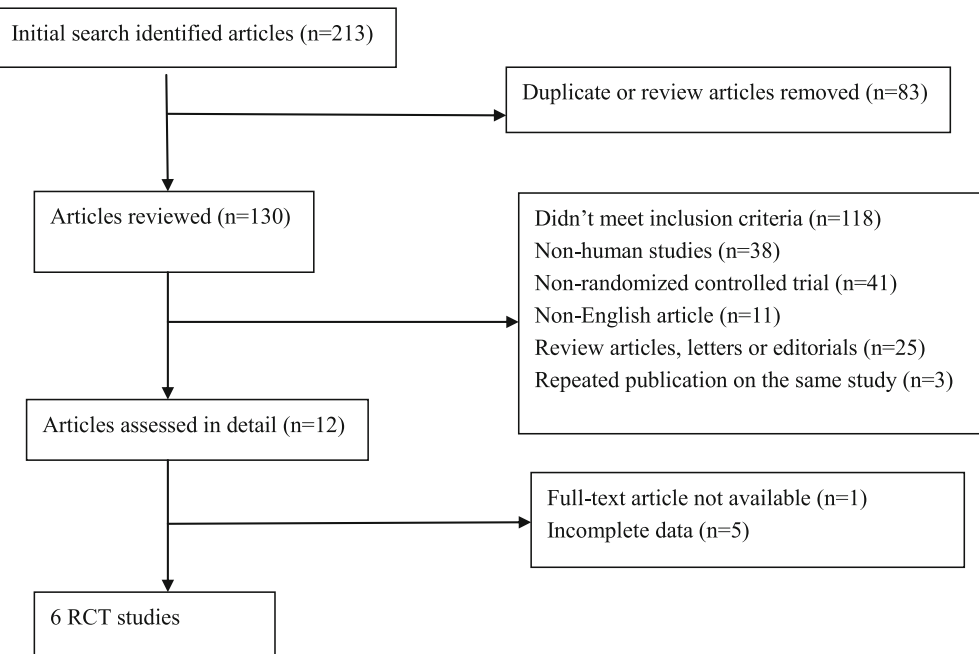

Fig. 1 An adapted PRISMA flow diagram of the study selection process. RCT randomized controlled trial

The stability of the results was tested by sensitivity analysis which was conducted by showing that removing any one study would not affect the overall results of the effects of stem cell-based therapy. This suggests that any single study did not affect the overall results of the meta-analysis.

\section{Publication bias}

Publication bias was qualitatively examined using a funnel plot. As shown in Fig. 4, the distribution of the funnel plot was nearly symmetrical, suggesting no obvious evidence of publication bias.

\section{Discussion}

According to a report from the World Health Organization, an estimated 422 million adults were living with DM in 2016 [22]. In the United States, 9.3\% of the population has diabetes [23]. In China, $11.6 \%$ of adults are diabetic, making China's prevalence rate of DM the highest in the world [24]. The prevalence of diabetes is increasing rapidly; the prevalence among adults was high at $14.3 \%$ in the United States [25]. DFU is a major complication of DM, occurring in 15\% of those with diabetes and preceding $84 \%$ of all diabetes-related lower leg amputations [4]. In the United States, DFUs represent a substantial cost burden among Medicare beneficiaries with diabetes, suggesting a 1-year cost of US\$9-13 billion, in addition to the costs associated with the disease itself [26].

We present here the results of a systematic review and meta-analysis of RCTs complete with figures and a table (all original work from our team) where autologous stem cell treatment was administered to patients with DFUs. Our analysis suggests that stem cell treatment is safe and significantly helps diabetic ulcer healing, without any increased risk of treatment-related adverse events. To our knowledge, our study is the first meta-analysis evaluating

Table 1 Characteristics of the included studies

\begin{tabular}{|c|c|c|c|c|c|c|c|c|c|}
\hline Study & $\begin{array}{l}\text { Mean age } \\
\text { (years) }\end{array}$ & $\begin{array}{l}\text { Participant cases } \\
\text { (treatment group) }\end{array}$ & $\begin{array}{l}\text { Stem } \\
\text { cell type }\end{array}$ & $\begin{array}{l}\text { Baseline ulcer } \\
\text { size }\left(\mathrm{cm}^{2}\right)\end{array}$ & Cell number & Delivery method & Placebo & $\begin{array}{l}\text { Follow-up } \\
\text { duration (weeks) }\end{array}$ & $\begin{array}{l}\text { Adverse } \\
\text { events }\end{array}$ \\
\hline Lu et al., 2011, China [18] & 65 & 11 & BMMNCS & 4.3 & NA & i.m. & N.S. & 24 & No \\
\hline Lu et al., 2011, China [18] & 63 & 11 & BMMSCS & 4.2 & NA & i.m. & N.S. & 24 & No \\
\hline $\begin{array}{l}\text { Huang et al., 2005, } \\
\text { China [19] }\end{array}$ & 71 & 18 & PBMNCS & 2.7 & $3 \times 10^{9} / \mathrm{leg}$ & i.m. & PGE1 & 12 & No \\
\hline $\begin{array}{l}\text { Kirana et al., 2012, } \\
\text { Germany [20] }\end{array}$ & 69 & 12 & BMMNCS & 9.6 & $3 \times 10^{8} / \mathrm{leg}$ & i.m. & No & 45 & No \\
\hline $\begin{array}{l}\text { Kirana et al., 2012, } \\
\text { Germany [20] }\end{array}$ & 71 & 12 & BMTRCS & 7.7 & $8 \times 10^{7} / \mathrm{leg}$ & i.m. & No & 45 & No \\
\hline $\begin{array}{l}\text { Han et al., 2010, } \\
\text { Korea [21] }\end{array}$ & 67 & 26 & PLA cells & 4.3 & $>4 \times 10^{6} /$ ulcer & Ad.us.ext. & No & 8 & No \\
\hline
\end{tabular}

Ad.us.ext. ad usum externum (for external use), BMMNCs bone marrow-derived mononuclear cells, BMMSCs bone marrow-derived mesenchymal stem cells, BMTRCs bone marrow-enriched tissue repair cells, i.m. intramuscularly, NA not available, N.S normal saline, PBMNCs peripheral blood-derived mononuclear cells, PGE1 Prostaglandin E1, PLA human processed lipoaspirate 


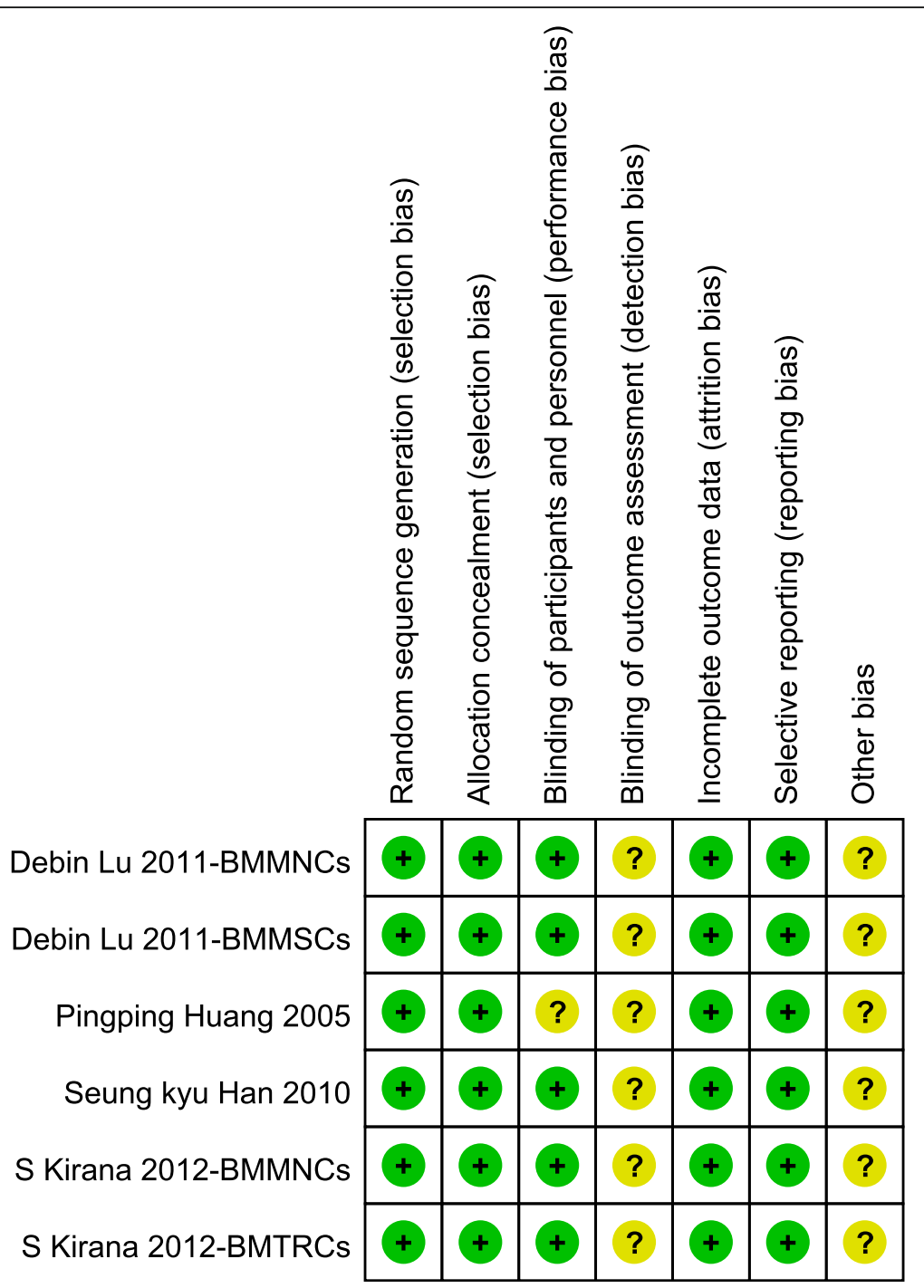

Fig. 2 Risk of bias for each included RCT. BMMNCs bone marrow-derived mononuclear cells, BMMSCs bone marrow-derived mesenchymal stem cells, BMTRCs bone marrow-enriched tissue repair cells

the use of autologous stem cells as an effective treatment strategy for DFUs. The stem cell treatment was not associated with any increased risk of adverse events.

The prevalence of leg ulcers in the general population is $0.12 \%$, but this rises to $1.2 \%$ in the population over 70 years of age. Two-thirds of pressure ulcers occur in patients who are over 70 years of age [27, 28]. Older adults with diabetes have significantly higher rates of major lower extremity amputation [29]. Considering the increasingly worsening general conditions and higher risks of traditional therapy, some older diabetic patients have a more immediate need for receiving stem cell treatment. However, advancing age negatively impacts stem cell function, and such age-related alterations may be detrimental for successful stem cell therapy [30, 31]. Duscher et al. [32] found that age-related changes in the mesenchymal stem cell population dynamics result in an impaired therapeutic potential of the aged progenitor cell. For older DFU patients, the efficacy of autologous stem cell transplantation is a clinical topic deserving attention. Our subgroup analysis suggests that stem cell treatment can effectively improve ulcer healing in diabetic patients $<70$ years of age, as well as those $\geq 70$ years of age. There are several possible reasons for this. First, biological functions of stem cells derived from an aged donor may be inferior to those derived from a younger donor, but both can enhance wound healing, especially in the hostile diabetic wound environment where many complicated factors may offset the difference in cells derived from aged and young donors. Second, only two research studies were included in our RCT subgroup of patients $\geq 70$ years of age, where the mean ages were 


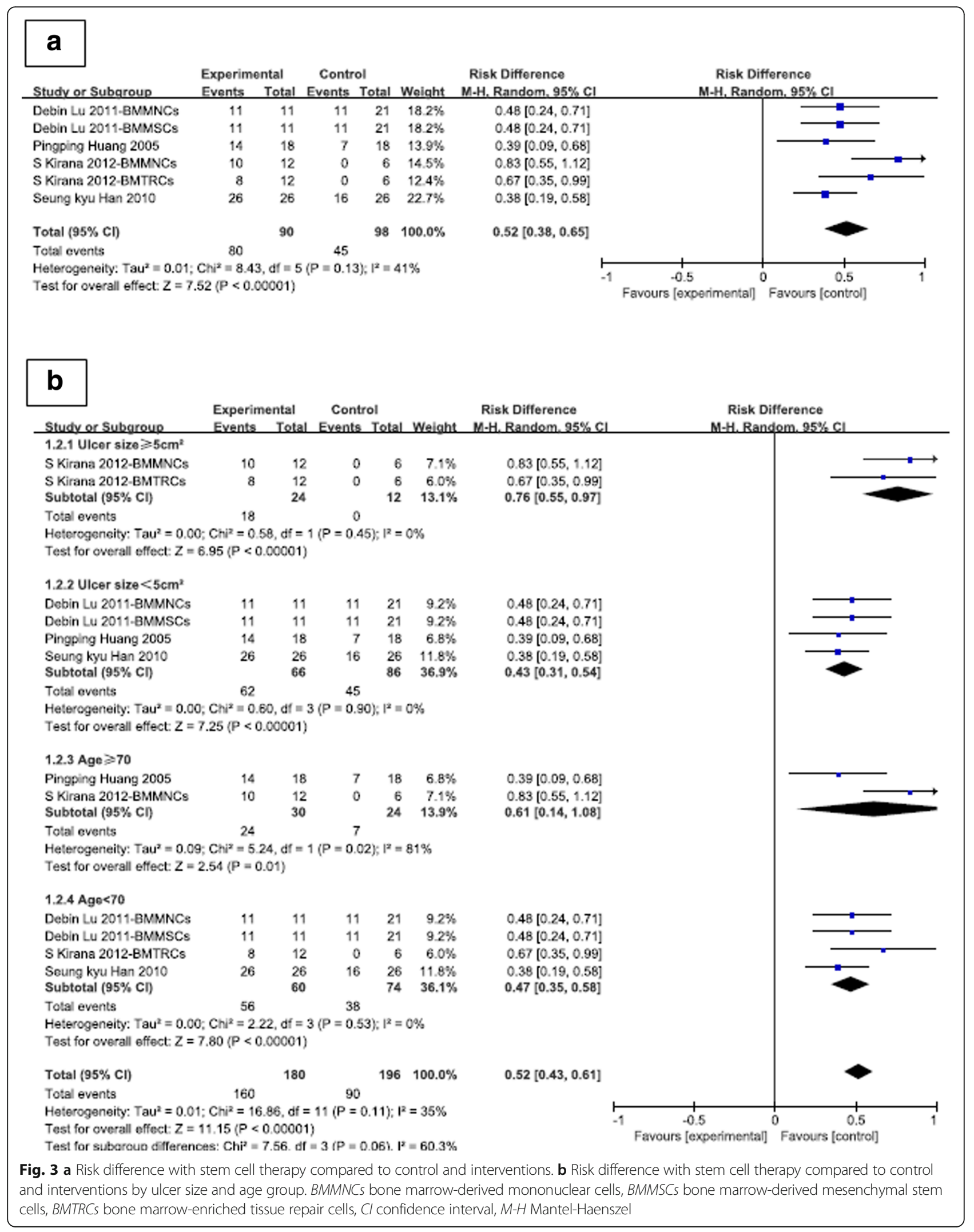




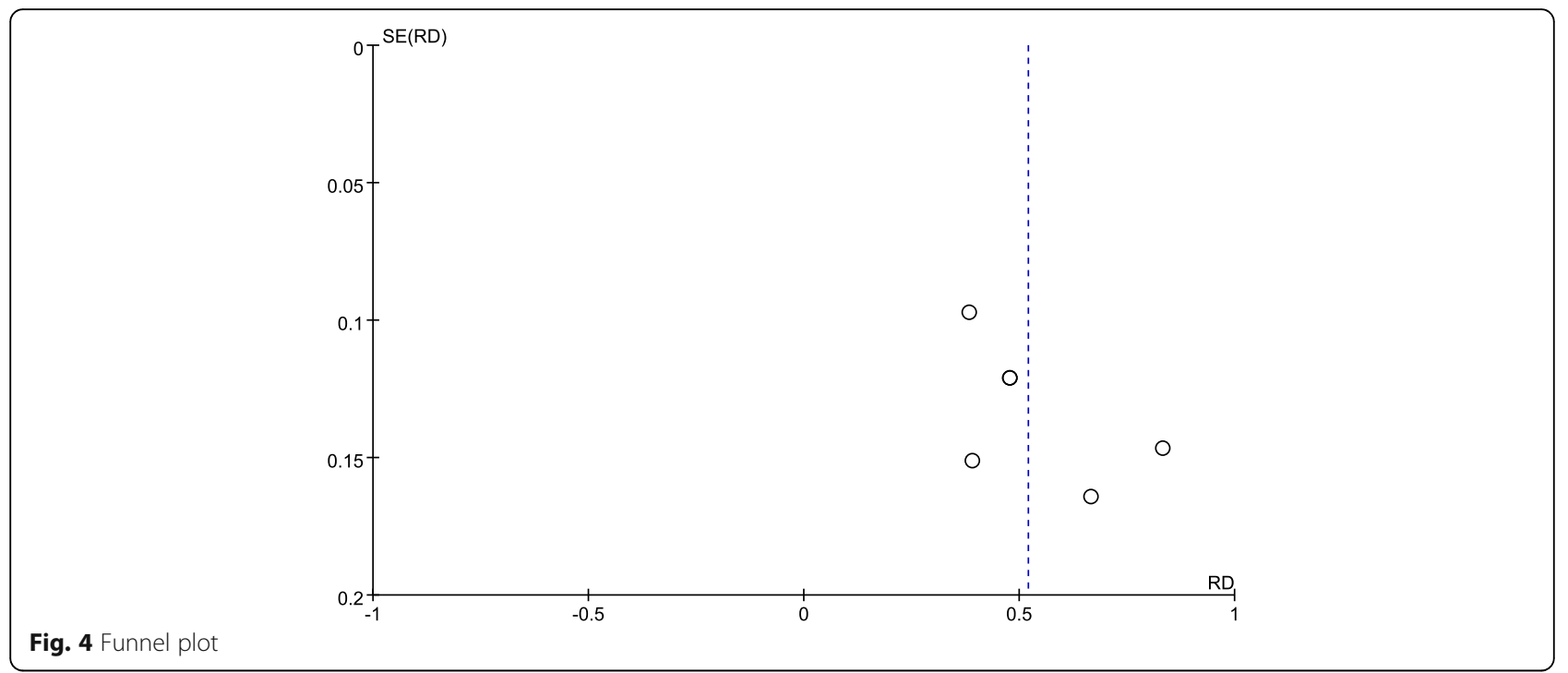

70.9 years and 71.1 years. Given that both studies had a mean age close to the age endpoint of 70 years, this may have interfered with the accuracy of the RCT study results. Jiang et al. evaluated the effects of autologous stem cells on lower extremity ulcers and found autologous stem cell-based therapy was associated with better healing of lower extremity ulcers [33]; however, this study focused on patients with lower extremity ulcers that included diabetic patients and the non-diabetic population. Considering diabetes foot ulcers have specificity and distinctive risk factors, DFU patients should be seen as an independent observational target. Sun et al. conducted a meta-analysis concluding that applying autologous stem cell transplantation for curing limb ischemia does not show any obvious improvement in the limb ischemia, but that it can dramatically reduce the rate of amputation [34]. This meta-analysis has two shortages: one is that this study only assessed limb ischemia and did not discuss DFU; another is that this is an early study, published in 2015, where all the enrolled articles were published before 2012. As new studies on stem cells have been published more recently, the meta-analysis should be updated to give physicians more up-to-date information and conclusions. To our knowledge, our study is the first meta-analysis on the associations of diabetic foot ulcer treatment with autologous stem cells.

Ulcer size may have a negative effect on the healing of DFUs [1, 15]. The results of Skardal et al. [35] suggest that stem cells could be an effective treatment for largescale wounds. In our analysis of the ulcer size subgroup, stem cell therapy had similar beneficial effects on the healing of both large and small ulcers $\left(\geq 5 \mathrm{~cm}^{2}\right.$ or $<5 \mathrm{~cm}^{2}$ ). This suggests that stem cell therapy may reduce the size of larger ulcers as well. Large diabetic cutaneous lesions typically have a poor blood supply, more serious tissue necrosis, inflammation, and bacterial contamination. The significant advantages of the application of regenerative therapies based on stem cells would be apt for this type of unfavorable environment [36]. As well as wound size, the wound depth, infection, and ischemia are also critical factors influencing wound healing [37]. Due to the limitations in article content, these parameters were not analyzed in our study.

The current study has several limitations. First, stem cell sources, the number of delivered cells, and the routes of cell administration differed among the studies. Due to these significant heterogeneities, optimized procedure protocols were not determined. Second, only the funnel plot was used to qualitatively assess publication bias, with no further examination by other methods such as Egger's regression. Third, the claim about the older subgroup is not fully justified since the selected studies were performed on patients aged 63, 65, 67, 69, and 71 years. There is no remarkable difference between these ages. Looking forwards, we need to include more studies conducted on patients with a wider age range. Fourth, the RCTs were small in scale and size, and evidence from larger samples and more rigorous RCTs are required.

\section{Conclusion}

This systematic review supports the promising role of stem cells in accelerating the healing of DFUs. Further evidence from larger, well-powered trials with long-term follow-up are needed to confirm our results.

\section{Abbreviations}

BMMNC: Bone marrow-derived mononuclear cell; BMMSC: Bone marrowderived mesenchymal stem cell; BMTRC: Bone marrow-enriched tissue repair cell; Cl: Confidence interval; DFU: Diabetic foot ulcer; DM: Diabetes mellitus; MD: Mean difference; PBMNC: Peripheral blood-derived mononuclear cell; 
PLA: Processed lipoaspirate; PRISMA: Preferred reporting items for systematic reviews and Meta-analyses; RCT: Randomized controlled trial

\section{Acknowledgments}

Not applicable.

\section{Funding}

This work is supported by grant no. XMLX201610 from the Beijing Municipal Administration of Hospitals Clinical Technology Innovation Program, grant no. DFL20150801 from the Beijing Municipal Administration of Hospitals Climbing Talent Training Program, grant no. 2016000020124G108 from the Beijing Outstanding Talents Project, and the Beijing Municipal Science and Technology Commission Clinical features Applied Research Projects Z141107002514063. These funding programs were not involved in the study design, in the collection, analysis and interpretation of data, in the writing of the report, or in the decision to submit the article for publication.

\section{Availability of data and materials}

Not applicable.

\section{Authors' contributions}

$\mathrm{RH}, J \mathrm{G}, \mathrm{AD}$, and $\mathrm{KF}$ participated in performing the research and data analysis. $\mathrm{RH}$ and $\mathrm{AD}$ contributed to research design, writing, and revising the manuscript. $Y G, K F$, and $A D$ participated in research design and data analysis. All authors read and approved the final manuscript.

\section{Ethics approval and consent to participate}

Not applicable.

\section{Consent for publication}

All authors agreed to publish this manuscript.

\section{Competing interests}

The authors declare that they have no competing interests.

\section{Publisher's Note}

Springer Nature remains neutral with regard to jurisdictional claims in published maps and institutional affiliations.

\section{Author details}

${ }^{1}$ Department of Vascular Surgery, Xuanwu Hospital, Capital Medical University, Beijing, China. ${ }^{2}$ Institute of Vascular Surgery, Capital Medical University, Beijing, China. ${ }^{3}$ Section of Vascular Surgery, Vascular Biology and Therapeutics, Yale University, New Haven, CT, USA. ${ }^{4}$ Yale University, New Haven, CT, USA. ${ }^{5}$ Occupational and Environmental Health, Xiangya School of Public Health, Central South University, Hunan, China.

\section{Published online: 16 October 2017}

\section{References}

1. Alexiadou K, Doupis J. Management of diabetic foot ulcers. Diabetes Ther. 2012;3(1):4.

2. Armstrong DG, Boulton AJM, Bus SA. Diabetic foot ulcers and their recurrence. N Engl J Med. 2017;376(24):2367-75.

3. Lauterbach S, Kostev K, Kohlmann T. Prevalence of diabetic foot syndrome and its risk factors in the UK. J Wound Care. 2010;19(8):333-7.

4. Dekker RG, Qin C, Ho BS, Kadakia AR. The effect of cumulative glycemic burden on the incidence of diabetic foot disease. J Orthop Surg Res. 2016;11(1):143.

5. Lipsky BA, Berendt AR, Cornia PB, Pile JC, Peters EJ, Armstrong DG, Deery HG, Embil JM, Joseph WS, Karchmer AW, Senneville E, Infectious Diseases Society of America, et al. Clinical practice guidelines for the diagnosis and treatment of diabetic foot infections. Clin Infect Dis. 2012;54(12):132-73.

6. Weledji EP, Fokam P. Treatment of the diabetic foot-to amputate or not? BMC Surg. 2014;14:83.

7. Humphries MD, Brunson A, Li CS, Melnikow J, Romano PS. Amputation trends for patients with lower extremity ulcers due to diabetes and peripheral artery disease using statewide data. J Vasc Surg. 2016;64(6):1747-55. e1743.

8. Hartmann B, Fottner C, Herrmann K, Limbourg T, Weber MM, Beckh K. Interdisciplinary treatment of diabetic foot wounds in the elderly: low risk of amputations and mortality and good chance of being mobile with good quality of life. Diab Vasc Dis Res. 2017;14(1):55-8.
9. Dinh T, Tecilazich F, Kafanas A, Doupis J, Gnardellis C, Leal E, Tellechea A, Pradhan L, Lyons T, Giurini JM, et al. Mechanisms involved in the development and healing of diabetic foot ulceration. Diabetes Care. 2012; 61(11):2937-47.

10. Yang M, Sheng L, Zhang TR, Li Q. Stem cell therapy for lower extremity diabetic ulcers: where do we stand? Biomed Res Int. 2013;2013:462179.

11. Kirby GT, Mills SJ, Cowin AJ, Smith LE. Stem cells for cutaneous wound healing. Biomed Res Int. 2015;2015:285869.

12. Huang PP, Yang XF, Li SZ, Wen JC, Zhang Y, Han ZC. Randomised comparison of G-CSF-mobilized peripheral blood mononuclear cells versus bone marrow-mononuclear cells for the treatment of patients with lower limb arteriosclerosis obliterans. Thromb Haemost. 2007;98(6):1335-42.

13. Smedley J, Michael GM, Tamire YG. Wound closure in smoking peripheral arterial disease patients with treatment-refractory ulcerations: a 12-month follow-up case series. Int J Low Extrem Wounds. 2016;15(4):360-5.

14. Costa RHR, Cardoso NA, Procópio RJ, Navarro TP, Dardik A, de Loiola Cisneros $L$. Diabetic foot ulcer carries high amputation and mortality rates, particularly in the presence of advanced age, peripheral artery disease and anemia. Diabetes Metab Syndr. 2017;12.

15. Marston WA, Group DDFUS. Risk factors associated with healing chronic diabetic foot ulcers: the importance of hyperglycemia. Ostomy Wound Manage. 2006;52(3):26-8.

16. Moher D, Liberati A, Tetzlaff J, Altman DG, Group P. Preferred reporting items for systematic reviews and meta-analyses: the PRISMA statement. J Clin Epidemiol. 2009;62(10):1006-12.

17. Hutton B, Moher D, Cameron C. The PRISMA extension statement. Ann Int Med. 2015;163(7):566-7.

18. Lu D, Chen B, Liang Z, Deng W, Jiang Y, Li S, Xu J, Wu Q, Zhang Z, Xie B, et al. Comparison of bone marrow mesenchymal stem cells with bone marrow-derived mononuclear cells for treatment of diabetic critical limb ischemia and foot ulcer: a double-blind, randomized, controlled trial. Diabetes Res Clin Pract. 2011;92(1):26-36.

19. Huang P, Li S, Han M, Xiao Z, Yang R, Han Z. Autologous transplantation of granulocyte colony-stimulating factor-mobilized peripheral blood mononuclear cells improves critical limb ischemia in diabetes. Diabetes Care. 2005:28(9):2155-60.

20. Kirana S, Stratmann B, Prante C, Prohaska W, Koerperich H, Lammers D, Gastens M, Quast T, Negrean M, Stirban O, et al. Autologous stem cell therapy in the treatment of limb ischaemia induced chronic tissue ulcers of diabetic foot patients. Int J Clin Pract. 2012;66(4):384-93.

21. Han S, Kim H, Kim W. The treatment of diabetic foot ulcers with uncultured, processed lipoaspirate cells: a pilot study. Wound Repair Regen. 2010;18(4):342-8.

22. WHO. Global report on diabetes. Geneva: WHO; 2016.

23. American Diabetes Association. National diabetes statistics report. 2014. https://www.cdc.gov/media/releases/2014/p0610-diabetes-report.html.

24. Xu Y, Wang L, He J, Bi Y, Li M, Wang T, Wang L, Jiang Y, Dai M, Lu J, et al. Prevalence and control of diabetes in Chinese adults. JAMA. 2013;310(9): 948-59.

25. Magliano DJ, Zimmet P, Shaw J. US trends for diabetes prevalence among adults. JAMA. 2016;315(7):705.

26. Rice JB, Desai U, Cummings AK, Birnbaum HG, Skornicki M, Parsons NB. Burden of diabetic foot ulcers for medicare and private insurers. Diabetes Care. 2014;37(3):651-8.

27. Clarke-Moloney M, Keane N, Kavanagh E. An exploration of current leg ulcer management practices in an Irish community setting. J Wound Care. 2006; 15(9):407-10.

28. Landi F, Onder G, Russo A, Bernabei R. Pressure ulcer and mortality in frail elderly people living in community. Arch Gerontol Geriatr. 2007;44 Suppl 1:217-23.

29. Li Y, Burrows NR, Gregg EW, Albright A, Geiss LS. Declining rates of hospitalization for nontraumatic lower-extremity amputation in the diabetic population aged 40 years or older: US, 1988-2008. Diabetes Care. 2012; 35(2):273-7.

30. Choudhery MS, Badowski M, Muise A, Pierce J, Harris DT. Donor age negatively impacts adipose tissue-derived mesenchymal stem cell expansion and differentiation. J Transl Med. 2014;12(8). doi:10.1186/14795876-12-8.

31. Beane OS, Fonseca VC, Cooper LL, Koren G, Darling EM. Impact of aging on the regenerative properties of bone marrow-, muscle-, and adipose-derived mesenchymal stem/stromal cells. PLoS One. 2014;9(12):e115963.

32. Duscher D, Rennert R, Januszyk M, Anghel E, Maan Z, Whittam A, Perez M, Kosaraju R, Hu M, Walmsley G, et al. Aging disrupts cell subpopulation 
dynamics and diminishes the function of mesenchymal stem cells. Sci Rep. 2014;4:7144.

33. Jiang $X$, Zhan $H$, Teng M. Effectiveness of autologous stem cell therapy for the treatment of lower extremity ulcers. Medicine. 2016;96(11):1-8.

34. Sun X, Ying J, Wang Y, Li W, Wu Y, Yao B, Liu Y, Gao H, Zhang X. Metaanalysis on autologous stem cell transplantation in the treatment of limb ischemic. Int J Clin Exp Med. 2015;8(6):8740-8.

35. Skardal A, Mack D, Kapetanovic E, Atala A, Jackson J, Yoo J, Soker S. Bioprinted amniotic fluid-derived stem cells accelerate healing of large skin wounds. Stem Cells Transl Med. 2012;1 (11):792-802.

36. Zubin E, Conti V, Leonardi F, Zanichelli S, Ramoni R, Grolli S. Regenerative therapy for the management of a large skin wound in a dog. Clin Case Rep. 2015;3(7):598-603.

37. Schaper NC, Van Netten JJ, Apelqvist J, Lipsky BA, Bakker K, International Working Group on the Diabetic Foot (IWGDF). Prevention and management of foot problems in diabetes: a summary guidance for daily practice 2015, based on the IWGDF guidance documents. Diabetes Res Clin Pract. 2017; 124:84-92. 